\title{
Non-Conducting Poly(O-Aminophenol) Films in the Field of the Bioelectrochemistry
}

\author{
Ricardo Tucceri \\ Instituto de Investigaciones Fisicoquímicas Teóricas y Aplicadas (INIFTA), CONICET, Facultad de Ciencias Exactas, UNLP, \\ Sucursal 4, Casilla de Correo 16, La Plata, Argentina \\ Email: rtucce@gmail.com
}

Received April 4, 2013; revised May 5, 2013; accepted June 1, 2013

Copyright (C) 2013 Ricardo Tucceri. This is an open access article distributed under the Creative Commons Attribution License, which permits unrestricted use, distribution, and reproduction in any medium, provided the original work is properly cited.

\begin{abstract}
The practical use of non-conducting poly(o-aminophenol) (POAP) films in the field of the bioelectrochemistry is discussed in this paper. Particular emphasis is given to the effects of applied potential, solution $\mathrm{pH}$ and interferents on the response current of biosensors based on POAP.
\end{abstract}

Keywords: Poly(O-Aminophenol); Biosensor; Amperometric Response; Glucose; Uric Acid; Hydrogen Peroxide; Lactate; Nicotinamide Coenzymes

\section{Introduction}

Electron-conducting polymers can easily be switched between different states, just by changing the potential, i.e. by electrochemical oxidation and reduction. During this transformation, a new polymeric material, which has chemical and physical properties substantially different from the initial one, is created. In these materials, besides the transport of species throughout the polymer film and the ion exchange at the polymer film-solution interface, a faradaic process occurs at the metal surface contacting the polymer film by electron transfer with the metal. These different processes are affected not only by the change of potential but also by changes in composition of the contacting fluid medium, e.g. varying $\mathrm{H}^{+}$concentration and film thickness [1].

Poly(o-aminophenol) (POAP) [2-7] is a ladder polymer whose redox reaction was considered as an internal conversion between oxidized and reduced units that can be represented by the stoichiometry shown in Figure 1 [8].

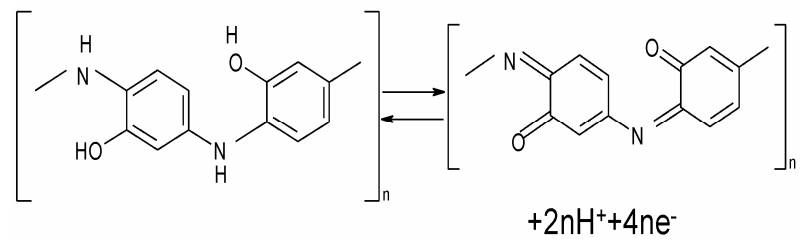

Figure 1. Stoichiometry of redox reactions of POAP film electrodes [8].
The polarization of POAP, at potentials which are more positive than $0.1 \mathrm{~V}$ (SCE), transforms the polymer predominantly into the quinonoid form, whereas the reduced units predominate only at negative potentials. This redox conversion of POAP must be accompanied by the proton exchange between the polymer and the solution. In this regard, the voltammetric response of POAP is highly dependent on the $\mathrm{pH}$, being optimal at $\mathrm{pH} 3$. At $\mathrm{pH}$ close to 5, the cathodic peak disappears completely, while for the anodic peak, this occurs at $\mathrm{pH} 7$ [9]. Parameters characterizing charge-transfer and charge-transport process at POAP films and their dependences on the external electrolyte contacting the polymer have been estimated using different techniques [10-20]. On the basis of impedance measurements, it is found that both ion and electron conductivities of POAP decrease as the solution $\mathrm{pH}$ increases [12,15]. The potential is another critical external variable that affects the electrochemical behavior of POAP. It was demonstrated that POAP remains electroactive when the potential is cycled from $-0.2 \mathrm{~V}$ to $0.5 \mathrm{~V}$ (vs. SCE). However, POAP suffers irreversible deterioration when the positive potential limit extends to values higher than a threshold value of $0.5 \mathrm{~V}$ (vs. SCE) [14]. Rotating Disc Electrode Voltammetry experiments demonstrate that the electron conductivity of POAP decreases as the polymer becomes more degraded [21]. On the basis of the Surface Resistance (SR) technique, this effect is attributed to a more extended configuration of redox sites at the metal-POAP interface after degradation, as 
compared with that of a film cycled only between $-0.2 \mathrm{~V}$ $<E<0.5 \mathrm{~V}$ (vs. SCE) [14]. With regard to POAP film thickness, it is observed that POAP films (thickness between $0.2 \mu \mathrm{m}$ and $0.5 \mu \mathrm{m}$ ) deposited on ITO electrodes are compact and continuous with a uniform thickness over the whole film [3]. Also, by employing POAP-coated gold film electrodes, it was possible to ensure that species of the external electrolyte do not interact with the thin gold film employed as base metal to deposit the polycmer [12]. In the same sense, a study [22] about the permeability of POAP films to different redox ion species $\left(\mathrm{Br}^{-}, \mathrm{I}^{-}, \mathrm{Tl}^{+}, \mathrm{Fe}(\mathrm{CN})^{3-}, \mathrm{Cu}^{2+}, \mathrm{Cd}^{2+}, \mathrm{Mn}^{+2}, \mathrm{Co}^{2+}\right.$ and $\mathrm{Cr}^{3+}$ ) showed that all the redox ions analyzed were unable to penetrate into POAP films, other than the $\mathrm{Tl}^{+}$ion which was able to partly permeate the films.

Despite a great number of studies reported in the literature about POAP synthesized in acidic media [2,3,5-8, $10-21]$, there is relatively little work that has been reported about electrochemistry of poly(o-aminophenol) in neutral and alkaline solutions [23]. POAP formed in neutral media leads to a nonconducting film that exhibits some advantages over the conducting film formed in acidic media. The film thickness of a nonconducting polymer is self controlled during electropolymerization, and a very thin and uniform film can be obtained. Also, nonconducting films prevent the diffusion of electroactive species from the electrolyte solution. These characteristic properties of POAP synthesized in neutral media (thickness uniformity and compactness, and low permeability) have practical applicability. POAP has usefully been employed in the development of different types of sensors, mainly biosensors based on immobilized enzymes. Thin nonconducting POAP films are combined with different electroactive materials (carbon nanotubes, other polymers such as poly(o-phenylenediamine) and polypyrrole, hemoglobin, Prussian blue, etc.) in such a way that POAP acts as an effective barrier to protect the sensor from the interference of electroactive species. The permselectivity of a nonconducting POAP film synthesized at $\mathrm{pH}$ values over 3 was found to be suitable to reduce the effect of interferents, such as ascorbic acid, uric acid and acetaminophen, in different biosensors. Concerning the film thickness, a small number of polymerization cycles ( 15 cycles) are found to be sufficient to obtain a compact and permselective film.

In the following sections, the more relevant uses of poly(o-aminophenol) in the field of biosensors are presented. Special attention is paid to the influence of different external variables (applied potential, $\mathrm{pH}$ of the solution and film thickness) on the electrochemical performance of this polymer as a sensor component.

Although this review is not comprehensive it brings together much of the work around POAP and is intended to be of particular in biosensors applications, particularly in the analysis of real samples, e.g. human serum and milk. Also, some results from basic research are included to explain the behavior of biosensors in their practical applications.

\section{Biosensors Based on POAP}

\subsection{Glucose Biosensors}

Recently, the development of glucose biosensors has received considerable attention because the determination of glucose concentration is very important in clinical applications. Most glucose measurements are based on the immobilization of glucose oxidase (GOx) for detecting hydrogen peroxide concentration, which is produced from the GOx enzyme reaction. Since GOx can recognize glucose target molecules quickly and accurately in complicated systems, a suitable matrix on the base electrode surface should be well designed for the immobilization of GOx while maintaining its highly enzymatic activity. The entrapment of GOx in electropolymerized films is a simple and efficient way to develop glucose sensors with high sensitivity, good stability and fast response. The entrapping technique should control the layer thickness and enzyme loading, while keeping the enzyme highly bioactive. So far, most work in this area has focused on the use of electropolymerized conducting films of polypyrrole (Ppy) [24,25] and its derivatives [26] and polyaniline (PANI) [27]. However, the recent literature seems to show increasing attention to some electropolymerized nonconducting polymers such as POAP. Biosensors based on POAP generally have the advantages of fast response and high sensitivity because of relatively high enzyme loading. Besides, the noncomducting POAP films are generally found to be more effective than the conducting ones in both preventing the biosensor from fouling and eliminating the interference from electroactive species such as ascorbic acid and uric acid.

Several glucose biosensors based on POAP are reported in the literature [28-32]. In most cases, hydrogen peroxide liberated by the enzymatic reaction is detected by measuring its oxidation current on the base electrode material (platinum, gold, glassy carbon, carbon paste, etc.). Glucose amperometric measurements are in general carried out with the sensor under stirred conditions, and the response current is considered in terms of the relationship between the steady-state current and background current (without glucose) changes. The composition of each one of these biosensors is described in this section. Table 1 shows the response characteristics of the biosensors.

Experimental conditions related to the preparation and characteristics of the $\mathrm{Pt} / \mathrm{PB} / \mathrm{POAP} / \mathrm{GOx}$ amperometric 
Table 1. Detection solutions and response characteristics of the different biosensors based on poly(0-aminophenol).

\begin{tabular}{|c|c|c|c|c|}
\hline Biosensor & Detection solution & $\begin{array}{l}\text { Electrochemical conditions and } \\
\text { response characteristics }\end{array}$ & Detection limit & Ref. \\
\hline $\mathrm{Pt} / \mathrm{PB} / \mathrm{POAP} / \mathrm{GOx}$ & $\begin{array}{l}1 / 15 \mathrm{M} \text { phosphate buffer solution } \\
(\mathrm{pH} 7) \text { containing different glucose } \\
\text { concentrations }(0-35 \mathrm{mM})\end{array}$ & $\begin{array}{l}\text { Operating potential, } \\
E=0.6 \mathrm{~V} \text { (vs. SCE). } \\
\text { Linear dependence of the current on } \\
\text { glucose concentration up to } 5 \mathrm{mM}\end{array}$ & $0.01 \mathrm{mM}$ & \multirow{2}{*}{ [28] } \\
\hline $\mathrm{Pt} / \mathrm{POAP} / \mathrm{GOx}$ & $\begin{array}{l}1 / 15 \mathrm{M} \text { phosphate buffer solution } \\
(\mathrm{pH} 7) \text { containing different glucose } \\
\text { concentrations }(0-60 \mathrm{mM})\end{array}$ & $\begin{array}{l}\text { Operating potential, } \\
E=0.6 \mathrm{~V} \text { (vs. SCE). } \\
\text { Linear dependence of the current on } \\
\text { glucose concentration up to } 10 \mathrm{mM}\end{array}$ & $0.02 \mathrm{mM}$ & \\
\hline GC/BCNT/POAP-GOx & $\begin{array}{l}1 / 15 \mathrm{M} \text { phosphate buffer solution } \\
(\mathrm{pH} 7) \text { containing different glucose } \\
\text { concentrations }(0-25 \mathrm{mM})\end{array}$ & $\begin{array}{l}\text { Operating potential, } \\
E=0.6 \mathrm{~V} \text { (vs. SCE). } \\
\text { Linear dependence of the current on } \\
\text { glucose concentration up to } 8 \mathrm{mM}\end{array}$ & $3.6 \mu \mathrm{M}$ & [29] \\
\hline $\mathrm{Au} / \mathrm{POAP} / \mathrm{CNT} / \mathrm{GOx}$ & $\begin{array}{l}1 / 15 \mathrm{M} \text { phosphate buffer solution } \\
(\mathrm{pH} 7) \text { containing different glucose } \\
\text { concentrations }(0-50 \mathrm{mM})\end{array}$ & $\begin{array}{l}\text { Operating potential, } \\
E=0.75 \mathrm{~V} \text { (vs. SCE). } \\
\text { Linear dependence of the current on } \\
\text { glucose concentration up to } 5 \mathrm{mM}\end{array}$ & $0.01 \mathrm{mM}$ & \multirow{2}{*}[30]{} \\
\hline $\mathrm{Au} / \mathrm{POAP} / \mathrm{GOx}$ & $\begin{array}{l}\text { 1/15 } \mathrm{M} \text { phosphate buffer solution } \\
(\mathrm{pH} 7) \text { containing different glucose } \\
\text { concentrations }(0-50 \mathrm{mM})\end{array}$ & $\begin{array}{l}\text { Operating potential, } \\
E=0.75 \mathrm{~V} \text { (vs. SCE). } \\
\text { Linear dependence of the current on } \\
\text { glucose concentration up to } 10 \mathrm{mM}\end{array}$ & $0.02 \mathrm{mM}$ & \\
\hline PGCE/POAP/GOx & $\begin{array}{l}\text { A stirred, air-saturated } 0.05 \mathrm{M} \\
\text { phosphate buffer (pH 7) solution, } \\
\text { where aliquots of glucose were } \\
\text { added. }\end{array}$ & $\begin{array}{l}\text { Operating potential, } E=0.6 \mathrm{~V} \text { (vs. } \\
\text { SCE), } \\
\text { The linear response of the enzyme } \\
\text { electrode to glucose was from } \\
1 \times 10^{-6} \text { to } 1 \times 10^{-3} \mathrm{M}\end{array}$ & $5 \times 10^{-7} \mathrm{M}$ & [30] \\
\hline POAP-GOx/PPy-Pt/GCE & $\begin{array}{l}\text { Stirred solution containing } 25 \mathrm{ml} \\
\text { air-saturated } 0.1 \mathrm{M} \mathrm{PBS}, \mathrm{pH} 7, \\
\text { where glucose was injected using a } \\
\text { micro-syringe }\end{array}$ & $\begin{array}{l}\text { Operating potential, } \\
E=0.60 \mathrm{~V} \text { (vs. SCE). } \\
\text { Linear dependence of the current on } \\
\text { glucose concentration from } 0.0015 \\
\mathrm{mM} \text { to } 13 \mathrm{mM} .\end{array}$ & $0.45 \mu \mathrm{M}$ & \multirow{2}{*}[32]{} \\
\hline POAP-GOx/Pt/GCE & $\begin{array}{l}\text { Stirred solution containing } 25 \mathrm{ml} \\
\text { air-saturated } 0.1 \mathrm{M} \mathrm{PBS,} \mathrm{pH} 7, \\
\text { where glucose was injected using a } \\
\text { micro-syringe }\end{array}$ & $\begin{array}{l}\text { Operating potential, } \\
E=0.60 \mathrm{~V} \text { (vs. SCE). } \\
\text { Linear dependence of the current on } \\
\text { glucose concentration from } 0.0042 \\
\mathrm{mM} \text { to } 12 \mathrm{mM} \text {. }\end{array}$ & $0.90 \mu \mathrm{M}$ & \\
\hline POAP-GOx/PPy/GCE & $\begin{array}{l}\text { Stirred solution containing } 25 \mathrm{ml} \\
\text { air-saturated } 0.1 \mathrm{M} \mathrm{PBS,} \mathrm{pH} 7, \\
\text { where glucose was injected using a } \\
\text { micro-syringe }\end{array}$ & $\begin{array}{l}\text { Operating potential, } \\
E=0.60 \mathrm{~V} \text { (vs. SCE). } \\
\text { Linear dependence of the current on } \\
\text { glucose concentration from } 0.0055 \\
\mathrm{mM} \text { to } 12 \mathrm{mM} \text {. }\end{array}$ & $0.95 \mu \mathrm{M}$ & [32] \\
\hline $\mathrm{Hb} / \mathrm{POAP} / \mathrm{FeCoHCF} / \mathrm{Au}$ & $\begin{array}{l}\text { Aliquots of a standard solution of } \\
\mathrm{H}_{2} \mathrm{O}_{2} \text { added to an acetate buffer } \\
\text { solution ( } \mathrm{pH} \text { 5.29) }\end{array}$ & $\begin{array}{l}\text { Operating potential, } \\
E=-0.25 \mathrm{~V} \text { (vs. SCE). } \\
\text { Linear dependence of the current on } \\
\text { the } \mathrm{H}_{2} \mathrm{O}_{2} \text { concentration within the } \\
\text { range } 1.73 \times 10^{-5} \mathrm{M}-4.03 \times 10^{-3} \mathrm{M}\end{array}$ & $1.2 \times 10^{-5} \mathrm{M}$ & [22] \\
\hline \multirow[t]{2}{*}{ HRP-ferrocene/POAP } & $\begin{array}{l}\text { Batch mode: Hydrogen peroxide in } \\
0.1 \mathrm{M} \text { phosphate solution }(\mathrm{pH} 8)\end{array}$ & $\begin{array}{l}\text { Rotating Disc Electrode } \\
\text { Voltammetry (RDEV). } \\
\text { Linear dependence of the current on } \\
\text { the } \mathrm{H}_{2} \mathrm{O}_{2} \text { concentration within the } \\
\text { range } 1 \times 10^{-8} \mathrm{M}^{-1} \times 10^{-5} \mathrm{M} \text {. } \\
\text { Detection potential: } 0.050 \mathrm{~V} \\
(\mathrm{Ag} / \mathrm{Ag} / \mathrm{Cl})\end{array}$ & $8.5 \times 10^{-9} \mathrm{M}$ & \multirow[t]{2}{*}[34]{} \\
\hline & $\begin{array}{l}\text { Flow Injection mode (FIA): } \\
\text { Hydrogen peroxide in } 0.1 \mathrm{M} \\
\text { phosphate solution }(\mathrm{pH} 8)\end{array}$ & $\begin{array}{l}\text { Consecutive injections ( } 50 \text { injections } \\
\text { per day for six days). } \\
\text { Linear dependence of the current on } \\
\text { the } \mathrm{H}_{2} \mathrm{O}_{2} \text { concentration within the } \\
\text { range } 1 \times 10^{-8} \mathrm{M}^{-2} \times 10^{-6} \mathrm{M} \text {. } \\
\text { Detection potential: } 0.050 \mathrm{~V} \\
(\mathrm{Ag} / \mathrm{Ag} / \mathrm{Cl})\end{array}$ & $8.5 \times 10^{-9} \mathrm{M}$ & \\
\hline
\end{tabular}




\begin{tabular}{|c|c|c|c|c|}
\hline Carbon paste/HRP-Uricase/POAP & $\begin{array}{l}\text { A stirred } 0.1 \mathrm{M} \text { solution of } \\
\text { phosphate buffer (pH 7.5) } \\
\text { containing uric acid. }\end{array}$ & $\begin{array}{l}\text { Operating potential, } E=0.050 \mathrm{~V} \\
\text { (vs. } \mathrm{Ag} / \mathrm{AgCl} \text { ). } \\
\text { Linear response up to } 1 \times 10^{-4} \mathrm{M} \text { of } \\
\text { urate }\end{array}$ & $3.14 \times 10^{-6} \mathrm{M}$ & \multirow{2}{*}[35]{} \\
\hline Carbon paste/HRP-Uricase/POAP & $\begin{array}{l}\text { Flow injection system: carrier } \\
\text { stream was } 0.1 \mathrm{M} \text { phosphate buffer } \\
(\mathrm{pH} 7.5) \text {. }\end{array}$ & $\begin{array}{l}\text { Operating potential, } E=0.050 \mathrm{~V} \\
\text { (vs. } \mathrm{Ag} / \mathrm{AgCl} \text { ). } \\
\text { Linear response up to } 1 \times 2 \times 10^{-4} \mathrm{M} \\
\text { of urate. Flow rate } 0.85 \mathrm{ml} \cdot \mathrm{min}^{-1} \text {. }\end{array}$ & $6.8 \times 10^{-6} \mathrm{M}$ & \\
\hline $\begin{array}{l}\text { Carbon paste/GPT-LDH- } \\
\text { NAD }^{+} / \text {PPD-POAP }\end{array}$ & $\begin{array}{l}0.1 \mathrm{M} \text { phosphate, } 0.01 \mathrm{M} \text { glutamate } \\
\text { solution, } \mathrm{pH} 9.5 \text {, containing lactate }\end{array}$ & $\begin{array}{l}\text { Operating potential, } E=0.0 \mathrm{~V} \text { (vs. } \\
\mathrm{Ag} / \mathrm{AgCl} \text { ). } \\
\text { Linear response to lactate up to } 8.5 \\
\times 10^{-5} \mathrm{M} \text {. }\end{array}$ & $6 \times 10^{-7} \mathrm{M}$ & [36] \\
\hline Carbon paste/POAP & $\begin{array}{l}0.1 \mathrm{M} \text { acetate buffer }(\mathrm{pH} 5) \text { solution } \\
\text { or } 0.1 \mathrm{M} \text { phosphate buffer }(\mathrm{pH} 7) \\
\text { solution, where NADH was added } \\
\text { in increments of } 1 \times 10^{-8} \mathrm{M} \text {. }\end{array}$ & $\begin{array}{l}\text { Operating potential, } E=0.15 \mathrm{~V} \text { (vs. } \\
\mathrm{Ag} / \mathrm{AgCl} \text { ). } \\
\text { Linear response of the catalytic } \\
\text { oxidation current from } 0 \mathrm{M} \text { to } 1 \times \\
10^{-7} \mathrm{M}(\mathrm{NADH})\end{array}$ & $1.0 \times 10^{-9} \mathrm{M}$ & {$[37]$} \\
\hline
\end{tabular}

glucose biosensor, which is based on the immobilization of glucose oxidase (Gox) in an electrochemically polymerized POAP film at a Prussian blue (PB)-modified platinum $(\mathrm{Pt})$ microelectrode, are described in [28]. While PB acts as a typical electroactive film that exhibits catalytic properties for $\mathrm{H}_{2} \mathrm{O}_{2}$ oxidation, the nonconducting POAP film acts as an effective barrier to protect the electrode from fouling. $\mathrm{PB}$ in the $\mathrm{Pt} / \mathrm{PB} / \mathrm{POAP} / \mathrm{GOx}$ biosensor leads to a lower detection limit and a larger response current as compared with the $\mathrm{Pt} / \mathrm{POAP} / \mathrm{GOx}$ electrode (Table 1). This difference was attributed to $\mathrm{PB}$, which allows a higher surface coverage of enzyme to be obtained due to the high surface roughness of the PB film. Also, PB molecules can be oxidized to Berlin green at high potentials, which electrocatalyzes the oxidation of hydrogen peroxide. However, the Pt/PB/POAP/GOx biosensor has a narrower linear range than the $\mathrm{Pt} / \mathrm{POAP} /$ GOx electrode. This characteristic was attributed to the poor operational stability and high decrease in sensitivity of the PB film.

A GC/BCNT/POAP-GOx glucose biosensor has been reported and is based on boron-doped carbon nanotubes (BCNT) and POAP films [29]. GOx was immobilized on the BCNT-modified glassy carbon electrode (GC/BCNT) by electrochemical copolymerization of GOx and o-AP. The GC/BCNT/POAP-GOx electrode exhibits better characteristics for glucose determination as compared with GC/BCNT and GC/BCNT/POAP electrodes. The better performance of the former biosensor was attributed to the presence of POAP that improves the stability and the anti-interferent ability of the electrode.

The Au/POAP/CNT/GOx amperometric glucose biosensor that is based on the immobilization of GOx in a composite film of POAP and carbon nanotubes (CNT), which are electrochemically copolymerized at a gold electrode, has been described [30]. Compared with the $\mathrm{Au} /$ $\mathrm{POAP} / \mathrm{GOx}$ biosensor, the $\mathrm{Au} / \mathrm{POAP} / \mathrm{CNT} / \mathrm{GOx}$ bio- sensor has a lower detection limit and a larger response current. While POAP can efficiently avoid the interference of electroactive compounds, CNT has the property of increasing the electron transfer.

The PGCE/POAP/GOx glucose biosensor based on the immobilization of GOx in an electropolymerized o-aminophenol (o-AP) polymer film on a platinized glassy carbon electrode is described in [31]. The porous platinum particle matrix of PGCE provided not only a large microscopic surface area for higher enzyme loading but also a desirable microenvironment to transform the enzymatically produced $\mathrm{H}_{2} \mathrm{O}_{2}$ more efficiently to an electronic signal. The POAP film acts as a permselective material in this sensor.

The fabrication and characterization of the POAPGOx/PPy-Pt/GCE glucose sensor based on a polypyrrole-platinum (PPy-Pt) composite-modified glassy carbon electrode (GCE), which was covered by a layer of POAP-GOx, are reported in [32]. The generated $\mathrm{H}_{2} \mathrm{O}_{2}$ can penetrate through the POAP film and be electrocatalytically oxidized at the PPy-Pt conducting nanocomposite. The fast response of this biosensor was attributed to the thin POAP film and the high dispersion of embedded Pt nanoclusters. The presence of the PPy-Pt nanocomposite in the POAP-GOx/PPy-Pt/GCE electrode leads to a lower detection limit and high sensitivity as compared with those of POAP-GOx/Pt/GCE and POAP-GOx/PPy/ GCE electrodes (Table 1).

\subsubsection{Influential Factors in the Response Characteristic of Glucose Biosensors Based on POAP}

The amperometric response characteristics of the enzyme electrodes based on POAP are affected by the thickness of the polymer film (polymerization cycle number), the $\mathrm{pH}$ of the detection solution, applied potential used in the determination, and the presence of electroactive (inter- 
fering) compounds. The effects of these factors on the behavior of glucose biosensors based on POAP are separately described.

\section{1) Effect of the polymerization cycle number of POAP films}

Thickness and morphology characteristics of electrochemically synthesized POAP films play an important role in the response current of glucose biosensors. In this regard, POAP synthesized in acidic media has some advantages over PANI. SEM examination shows that POAP deposits are denser and have a smoother appearance than PANI, deposited under similar experimental conditions [33]. Furthermore, thin POAP films have a characteristic smooth, continuous and denser appearance, which contrasts with electrochemically polymerized thin PANI films, which are not smooth but show a spot-like morphology. In the respect of thickness control, the vertical sectional profile of POAP films shows that they are continuous with the thickness being almost uniform over the whole film [3]. It has, however, been demonstrated that the compactness of POAP morphology prevents the diffusive penetration of dissolved oxygen, and POAP oxidation does not occur to the same extent as in PANI [33]. Also, in some cases the POAP film can be easily regenerated after use.

With the Pt/PB/POAP/GOx biosensor [28], it has been observed that the response current is affected by the film thickness of Prussian blue (PB) and POAP. In general, thick films show a long response time and low sensitivity, but result in a wider linear response range. When the polymerization cycle number was 15 for both $\mathrm{PB}$ and POAP, the maximum value of the response current was obtained. Also, for the POAP-GOx/PPy-Pt/GCE biosensor [32], the maximum current response was obtained when the polymerization cycle number for POAP-GOx was 15 . The response current of the $\mathrm{Au} / \mathrm{POAP} / \mathrm{CNT} / \mathrm{GOx}$ biosensor [30] also increases with the increase of the polymerization cycle number, until a maximum value of 15 cycles (Figure 2). It has been suggested that when the number of cycles is lower than 15, then the amount of enzyme entrapped in the POAP film gradually increases with the increase of the polymerization cycle number. However, when the number of cycles is higher than 15 , GOx may be covered by the POAP film, decreasing the available amount of GOx.

Morphologic studies of the PGCE/POAP/GOx biosensor [31] revealed the presence of a three-dimensional porous open structure. The aggregates of the electrodeposited $\mathrm{Pt}$ on the GC surface were fairly uniform and roughly spherical. The porous open structure provided a greatly enhanced effective electrode surface for high enzyme loading. When the PGCE was coated with an electropolymerized POAP film, the porous open structure was maintained, although the aggregates got bigger and

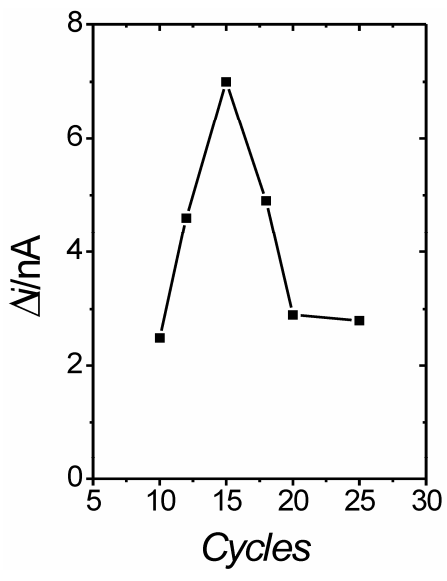

Figure 2. Effect of the polymerization cycle number on the response current of the Au/POAP/CNT/GOD electrode. Steady-state currents are measured at $0.75 \mathrm{~V}$ (SCE) in 1/15 M phosphate buffer solution (pH 7) containing $2 \mathrm{mM}$ glucose $(n=3)[30]$.

the surface became smoother because of the deposited POAP film. The polymerization of o-AP and immobilization of GOx were done either by holding them at a constant potential or by applying cyclic voltammetry (CV). Biosensors prepared by $\mathrm{CV}$ were more reproduceble and more effective in rejecting interferents. This was attributed to the fact that the film formed by $\mathrm{CV}$ was more uniform and compact than that formed at constant potential.

\section{2) Effect of the solution $\mathrm{pH}$}

In general, neutral buffer solutions ( $\mathrm{pH} 7)$ are selected for glucose detection with most of the biosensors based on POAP (Table 1). The response current of the $\mathrm{GC} /$ BCNT/POAP-GOx sensor [29] increases with the increase of the $\mathrm{pH}$ value, and the maximum response was observed at $\mathrm{pH}$ 7.0. Also, for the POAP-GOx/PPy-Pt/ GCE electrode [32], the current increased from $\mathrm{pH} 4.5$ to 7.0, while it decreased sharply above $\mathrm{pH}$ 7.0. The maximum current at $\mathrm{pH} 7.0$ was attributed to the entrapment of GOx in the POAP film, which made GOx more active in neutral solution. However, other biosensors show response currents as a function of $\mathrm{pH}$ where different maximum current values are observed. Figure 3 shows the response current of the $\mathrm{Pt} / \mathrm{PB} / \mathrm{POAP} / \mathrm{GOx}$ electrode [28] as a function of $\mathrm{pH}$. As can be seen, even though the biosensor can be used over a wide $\mathrm{pH}$ range $(\mathrm{pH} 4.5$ - 8), the maximum of the response current was observed at $\mathrm{pH} 7$. Again, this was attributed to the entrapment of GOx in the POAP film, making GOx more active in neutral media. However, at $\mathrm{pH} 5.6$ a high response current was also observed.

\section{3) Effect of the applied potential}

The response current of most glucose biosensors based on POAP [28-30,32] increases rapidly with the increase of the applied potential, and then, after a given potential 


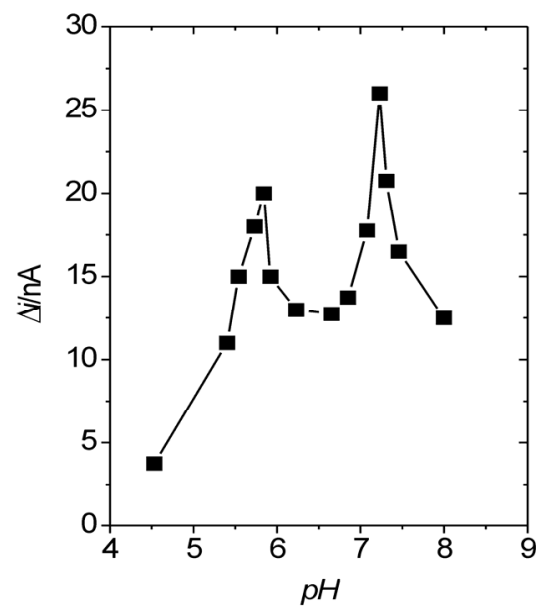

Figure 3. Effect of $\mathrm{pH}$ on the steady-state response current on the Pt/Prussian blue/poly(o-aminophenol)/glucose oxidase electrode at $0.6 \mathrm{~V}$ in $1 / 15 \mathrm{M}$ phosphate buffer solution (pH 7) containing $2 \mathrm{mM}$ glucose $(n=3)$ [28].

value, the response current remains constant. Figure 4 shows the response current as a function of the applied potential for the Au/POAP/CNT/GOx biosensor [30]. When the applied potential is below $0.75 \mathrm{~V}$ (vs. SCE) $(0.5 \mathrm{~V}-0.75 \mathrm{~V}$ vs. SCE), the response current increases rapidly with the increase of the applied potential. The response of the enzyme electrode in this potential range is controlled by the electrochemical oxidation of hydrogen peroxide. When the potential was over $0.75 \mathrm{~V}$, the response current remained almost the same. This effect was explained by the rate-limiting process of enzyme kinetics and substrate diffusion. However, it was also found that the higher the applied potential, the easier it is for the electroactive interferents to be oxidized and to cause an additional response current, and the easier it is for the polymer film to be damaged. Potential values lower than $0.8 \mathrm{~V}$ (SCE) are often therefore selected for the oxidation operation of the different enzyme electrodes (Table 1).

\section{4) Effect of the interferents}

Selectivity is one of the major characteristics of an amperometric glucose biosensor. The response of the sensor should be specific to a given analyte and should not involve other electroactive substances in the sample. With regard to the effects of interferents, the magnitude of the interferent current $\left(I_{\mathrm{G}+\mathrm{I}}\right)$ relative to the analytical signal $\left(I_{\mathrm{G}}\right)$ produced by the analyte (glucose) was considered in different biosensors [28-30]. The interferences of electroactive compounds in the glucose response were examined in the presence of their physiological normal levels $(0.1 \mathrm{mM}$ ascorbic acid (AA), $0.5 \mathrm{mM}$ uric acid (UA) and $0.1 \mathrm{mM}$ acetaminophen (AMP)) with a glucose concentration of $5.6 \mathrm{mM}$. It was observed that the influence of AA, UA and AMP on the glucose response was always small under the testing conditions. The ratio $I_{\mathrm{G}+\mathrm{I}}$ to $I_{\mathrm{G}}$ for different biosensors is shown in Table 2. The improved interferent behavior of these biosensors [28-30] was attributed to POAP films, which could efficiently avoid the interference of the above-mentioned electroactive compounds.

With the PGCE/POAP/GOx biosensor [31], it has been shown that POAP films can prevent the access of interferents such as AA, UA, and $\mathrm{Fe}(\mathrm{CN})^{4-}$ to the platinum surface, while allowing $60 \%$ of $\mathrm{H}_{2} \mathrm{O}_{2}^{6}$ to penetrate it. However, even though the interference from electroactive species such as AA and UA was significantly reduced by the use of the POAP film, the response of the sensor to ascorbate gradually increased when the sensor was stored for more than 3 months. This was attributed to the fall off or dissolution of the film into the solution. Nevertheless, the rejection efficiency could be restored by redeposition of POAP onto the electrode surface from a GOx-free o-AP solution for 2 minutes, although the biosensor suffers a loss of $30 \%$ of the electrode response to glucose.

An interference test was also made for the different

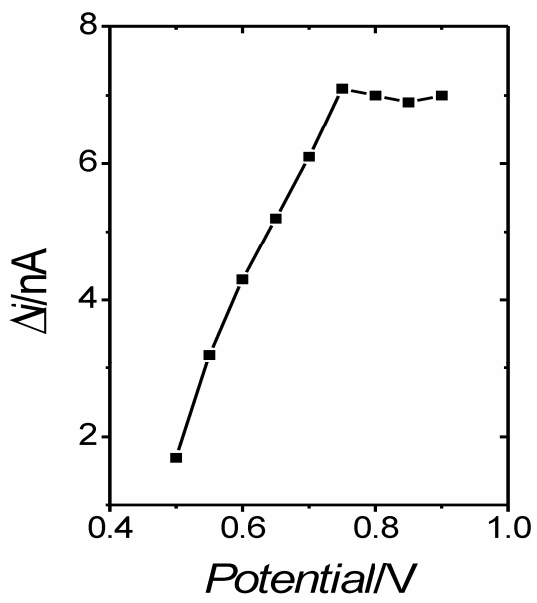

Figure 4. Effect of applied potential on the response current of the Au/POAP/CNT/GOD electrode. Steady-state currents are measured in 1/15 M phosphate buffer solution (pH 7) containing $2 \mathrm{mM}$ glucose [30].

Table 2. Interferences of electroactive compounds to the glucose response for different biosensors based on poly(oaminophenol). Mmagnitude of the interferent current $\left(I_{G+1}\right)$ relative to the analytical signal $\left(I_{G}\right)$ produced by the analyte (glucose).

\begin{tabular}{ccccc}
\hline Biosensor & $\begin{array}{c}\boldsymbol{I}_{\mathrm{G}+\mathrm{+}} / \mathbf{I}_{\mathrm{G}} \\
(\mathbf{A A})\end{array}$ & $\begin{array}{c}\boldsymbol{I}_{\mathrm{G}+\mathrm{I}} / \mathbf{I}_{\mathrm{G}} \\
(\mathbf{U A})\end{array}$ & $\begin{array}{c}\boldsymbol{I}_{\mathrm{G}+1} / \mathbf{I}_{\mathrm{G}} \\
(\mathbf{A M P})\end{array}$ & Ref. \\
\hline $\begin{array}{c}\mathrm{Pt} / \mathrm{PB} / \mathrm{POAP} / \mathrm{GOx} \\
\mathrm{GC} / \mathrm{BCNT} /\end{array}$ & 1.03 & 1.06 & 1.04 & {$[28]$} \\
$\begin{array}{c}\mathrm{POAP}-\mathrm{GOx} \\
\mathrm{Au} / \mathrm{POAP} / \mathrm{CNT} / \mathrm{GOx}\end{array}$ & 1.05 & 1.02 & 1.06 & {$[29]$} \\
\hline
\end{tabular}

Test conditions: $0.1 \mathrm{mM}$ ascorbic acid (AA), $0.5 \mathrm{mM}$ uric acid (UA) and 0.1 $\mathrm{mM}$ acetaminophen (AMP)) with a glucose concentration of $5.6 \mathrm{mM}$. 
electrodes synthesized in [32] (Table 1). To this end the amperometric responses of POAP-GOx/PPy-Pt/GCE and POAP-GOx/Pt/GCE to the consecutive additions of glucose, UA, AA and AMP were analyzed. The current response for $5.5 \mathrm{mM}$ glucose could be observed at both electrodes. However, the response of the POAP-GOx/Pt/ GCE electrodes was much smaller than that of the POAP-GOx/PPy-Pt/GCE electrode. This difference was attributed to Ppy electroactivity. Also, for successive additions of $0.5 \mathrm{mM}$ UA, $0.2 \mathrm{mM}$ AA and $2.0 \mathrm{mM}$ AMP to the glucose solution, the POAP-GOx/PPy-Pt/GCE electrode had nearly no response current from the interferents. The POAP-GOx/Pt/GCE electrode could also eliminate the influence of UA and AA. However, $2.0 \mathrm{mM}$ AMP had significant influence.

\section{5) Effect of the temperature}

Temperature is an important factor for the activity of the enzyme. The response of the POAP-GOx/PPy-Pt/GCE biosensor [32] was measured between $10^{\circ} \mathrm{C}$ and $60^{\circ} \mathrm{C}$. The current response increased almost linearly with temperature from $10^{\circ} \mathrm{C}$ to $40^{\circ} \mathrm{C}$, but decreased linearly from 40 to $60^{\circ} \mathrm{C}$. While the latter behavior was attributed to the deactivation of GOx, the former one was attributed to the increase in activity of the immobilized GOx. Thus, the activation energy $\left(25.9 \mathrm{~kJ} \cdot \mathrm{mol}^{-1}\right)$ of the immobilized GOx could be calculated on the basis of the Arrhenius equation. According to authors of [32], the PPy-Pt nanocomposite and POAP film offer a good environment for GOx, which makes the biosensor more stable at high temperature.

6) Stability of glucose biosensors

The stability under storage conditions (phosphate buffer of $\mathrm{pH} 7$ at low temperature) was analyzed for most of the glucose biosensors based on POAP.

After 7 days, an $8 \%$ loss of the response signal was observed for every day of use in the GC/BCNT/POAPGOx biosensor [29]. However, $80 \%$ response current was retained after 20 days. The $\mathrm{Au} / \mathrm{POAP} / \mathrm{CNT} / \mathrm{GOx}$ biosensor [30] showed that the $75 \%$ response current was still retained after 30 days of use. The good stability of these biosensors was attributed to the enzyme entrapped in the POAP film that is stable in neutral medium.

The Pt/PB/POAP/GOx biosensor [28] showed only $6 \%$ decrease of the original current response to glucose during the first 7 consecutive days of use. However, 75\% response current was still retained after 30 days (Figure 5). This behavior was attributed to the high decrease in sensitivity of the PB film.

The POAP-GOx/PPy-Pt/GCE electrode [32], showed no significant decrease in current response in the first 7 days of use. However, a decrease of $11 \%$ was observed after 30 days. A $76 \%$ response current was retained after 60 days. This good stability was attributed, firstly, to GOx molecules entrapped in the POAP film that are sta-

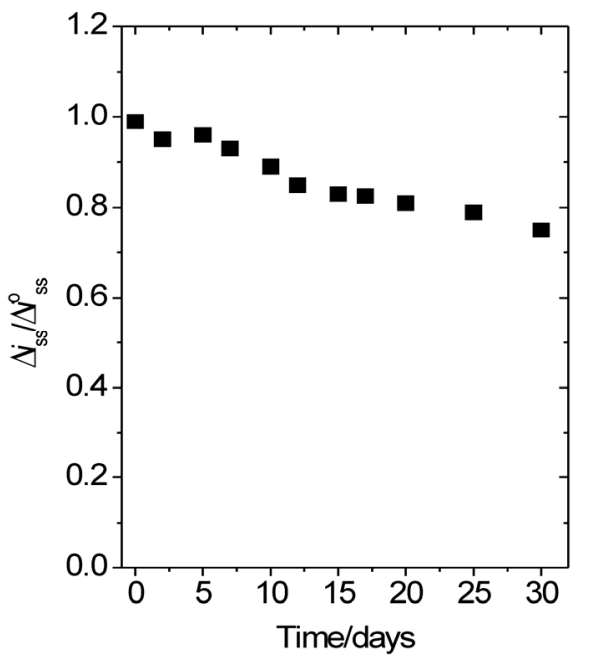

Figure 5. Stability of the Pt/Prussian blue/poly(o-aminophenol)/glucose oxidase electrode stored in 1/15 M phosphate buffer solution ( $\mathrm{pH} 7)$ at $4^{\circ} \mathrm{C}$. Stability determined by $5 \mathrm{mM}$ glucose in 1/15 M phosphate buffer solution (pH 7). Applied potential, 0.6 V (SCE) [28].

ble and retain bioactivity, and secondly, to the PPy-Pt nanocomposite structure, which provides a biologically compatible matrix for immobilizing the GOx-POAP film.

The stability of the PGCE/POAP/GOx electrode was found to be better than that of the PDE/POAP/GOx electrode [31] (Table 1). The difference was attributed to a slow desorption and deactivation of the GOx entrapped in the micropores of the platinized platinum particle marix, which are not as easy as on a smooth surface (platinum disc electrode).

7) Reproducibility and sensitivity of the biosensors

The reproducibility of the $\mathrm{Pt} / \mathrm{PB} / \mathrm{POAP} / \mathrm{GOx}$ electrode was analyzed in [28]. It was estimated from the response to $1 \mathrm{mM}$ glucose for five enzyme electrodes at a potential value of $0.6 \mathrm{~V}$ (SCE). The results revealed that the sensor exhibits satisfactory reproducibility with a mean change of the response current of $12.6 \mathrm{nA}$ and a relative standard deviation of $4.32 \%$. With regard to the sensitivity (44 $\mathrm{mA} \cdot \mathrm{M}^{-1}$ ) of the $\mathrm{Pt} / \mathrm{PB} / \mathrm{POAP} / \mathrm{GOx}$ electrode, it was nine times larger than that of the $\mathrm{Pt} / \mathrm{POAP} / \mathrm{GOx}$ electrode.

The GC/BCNT/POAP-GOx biosensor [29] showed good characteristics, such as high sensitivity (171.2 $\left.\mathrm{nA} \cdot \mathrm{mM}^{-1}\right)$, low detection limit $(3.6 \mu \mathrm{M})$, wide linear range (up to $8 \mathrm{mM}$ ) and short response time (within $6 \mathrm{~s}$ ).

The sensitivity reported for the $\mathrm{Au} / \mathrm{POAP} / \mathrm{CNT} / \mathrm{GOx}$ biosensor [30] is $11.4 \mathrm{~mA} \mathrm{M} \cdot \mathrm{cm}^{-2}$, this is almost 2.5 times higher than that of the $\mathrm{Au} / \mathrm{POAP} / \mathrm{GOx}$ electrode. With regard to reproducibility, the results revealed that the sensor has satisfactory reproducibility, with a mean change of the response current of $3.6 \mathrm{nA}$ and a relative standard deviation of $8.4 \%$.

The stability of the PGCE/POAP/GOx electrode [31] was evaluated by repetitive (200 times) measurements of 
its response to $1 \mathrm{mM}$ glucose within a period of $10 \mathrm{~h}$. The sensor sensitivity loss was only $14.3 \%$ after the 200 measurements. With intermittent usage and storage at $4^{\circ} \mathrm{C}$ in phosphate buffer for 10 months, the biosensor maintained $50 \%$ of its original sensitivity and still displayed an excellent response to glucose.

The lower detection limit $(0.45 \mu \mathrm{M})$ and high sensitivity $\left(9.9 \mathrm{~mA} / \mathrm{Mcm}^{2}\right)$ of the POAP-GOx/PPy-Pt/GCE $(0.45$ $\mu \mathrm{M})$ sensor [32], as compared with those of POAP-GOx/ $\mathrm{Pt} / \mathrm{GCE}\left(0.90 \mu \mathrm{M}\right.$ and $\left.5.5 \mathrm{~mA} / \mathrm{Mcm}^{2}\right)$ and POAP-GOX/ $\mathrm{PPy} / \mathrm{GCE}\left(0.95 \mu \mathrm{M}\right.$ and $\left.3.5 \mathrm{~mA} / \mathrm{Mcm}^{2}\right)$, respectively, were attributed to the presence of a Ppy-Pt nanocomposite system.

\section{8) Real sample analysis}

Human plasma samples were assayed to demonstrate the practical use of the GC/BCNT/POAP-GOx biosensor [29]. A plasma sample $(0.5 \mathrm{~mL})$ was added to $5 \mathrm{~mL}$ PBS $(\mathrm{pH} 7.0)$, and the response was obtained at $0.6 \mathrm{~V}$ (SCE). The contents of glucose in blood could then be calculated from the calibration curve (Table 1). The results obtained agreed closely (relative error between $1 \%$ and $3 \%$ ) with those obtained from a biochemical analyzer (ASCA AG II Chemistry System, Landmark, USA).

\subsection{Amperometric Hydrogen Peroxide Biosensors Based on POAP}

Two interesting sensors based on POAP for the direct determination of hydrogen peroxide are reported in the literature [22,34].

The immobilization of hemoglobin $(\mathrm{Hb})$ in POAP films at iron-cobalt hexacyanoferrate ( $\mathrm{FeCoHCF})$ films to build the $\mathrm{Hb} / \mathrm{POAP} / \mathrm{FeCoHCF} / \mathrm{Au}$ biosensor is reported in [22]. The FeCoHCF film was firstly deposited on the gold electrode and then it was combined with a POAP film that entraps $\mathrm{Hb}$. While the immobilized $\mathrm{Hb}$ in the $\mathrm{Hb} / \mathrm{POAP} / \mathrm{FeCoHCF} / \mathrm{Au}$ film exhibits catalytic activity to $\mathrm{H}_{2} \mathrm{O}_{2}$ by the mediation of $\mathrm{FeCoHCF}$, the POAP film reduces the interference from electroactive species.

The construction and characterization of a horseradish peroxidase (HRP)-ferrocene modified carbon paste biosensor, using an electrochemically generated POAP film (HRP-ferrocene/POAP), for the determination of hydrogen peroxide is reported in [34]. POAP in this biosensor was considered as a convenient means of immobilizing the enzyme and mediator on the electrode surface, while preventing electrode fouling.

\subsubsection{Influential Factors in the Response Characteristic of the $\mathrm{H}_{2} \mathrm{O}_{2}$ Biosensors Based on POAP}

1) Preparation of films employed in $\mathrm{H}_{2} \mathrm{O}_{2}$ biosensors

A series of FeCoHCF films were electrodeposited on gold electrodes from solutions containing $6 \mathrm{mM}$ $\mathrm{Fe}(\mathrm{CN})_{6}^{-3}$ with different concentrations of $\mathrm{Co}(\mathrm{II})$ and
$\mathrm{Fe}(\mathrm{III})$ to obtain the biosensor reported in [22]. The Fe$\mathrm{CoHCF}$ film deposited from a solution with an iron molar ratio of 0.4 showed the largest response current to $\mathrm{H}_{2} \mathrm{O}_{2}$. Therefore, the optimized FeCoHCF film was combined with a nonconducting POAP film that entraps $\mathrm{Hb}$ to construct the biosensor $\mathrm{Hb} / \mathrm{POAP} / \mathrm{FeCoHCF} / \mathrm{Au}$ electrode [22]. The electrochemical copolymerization of o$\mathrm{AP}$ and $\mathrm{Hb}$ on the $\mathrm{FeCoHCF} / \mathrm{Au}$ electrode was performed in a $5 \mathrm{mM}$ o-AP and $0.04 \mathrm{mM} \mathrm{Hb}$ acetate buffer solution $(\mathrm{pH} \mathrm{5.0)}$ where the electrode was cycled between -0.2 and $0.8 \mathrm{~V}$ (vs. SCE) at a scan rate of $50 \mathrm{mV} \cdot \mathrm{s}^{-1}$. All films used in [22] were grown for 15 cycles.

POAP films for the (HRP)-ferrocene modified carbon paste biosensor [34] were prepared by electropolymerization of a $5 \mathrm{mM}$ o-AP solution where the electrode was cycled (40 cycles) between 0.0 and $0.8 \mathrm{~V}$ (vs. $\mathrm{Ag} / \mathrm{AgCl}$ ) at a scan rate of $50 \mathrm{mV} \cdot \mathrm{s}^{-1}$. A fresh acetate buffer solution $(0.1 \mathrm{M}, \mathrm{pH}$ ) was employed as supporting electrolyte.

\section{2) Effect of the solution $\mathrm{pH}$}

With regard to the $\mathrm{pH}$ effect on the catalytic reduction current of the $\mathrm{Hb} / \mathrm{POAP} / \mathrm{FeCoHCF} / \mathrm{Au}$ electrode reported in [22], the maximum response current was observed at $\mathrm{pH}$ 5.29. This was attributed to the entrapment of $\mathrm{Hb}$ in the POAP film deposited on the FeCoHCF/Au electrode, making $\mathrm{Hb}$ more active in weak acidic medium. Considering the high bioactivity of $\mathrm{Hb}$ at this $\mathrm{pH}$ and the stability of the $\mathrm{Hb} / \mathrm{POAP} / \mathrm{FeCoHCF}$ film, $\mathrm{pH} 5.29$ was chosen as the $\mathrm{pH}$ value of the detection solution (Table 1).

Several experiments were carried out in [34] by using the (HRP-ferrocene/POAP) sensor coupled to a rotating disc electrode. Levich plots were obtained for different $\mathrm{H}_{2} \mathrm{O}_{2}$ concentrations in a $0.1 \mathrm{M}$ phosphate buffer solution at $\mathrm{pH}$. The steady-state current was found to be directly proportional to the square root of the angular rotation speed according to the Levich equation (Equation (1)) at concentrations of hydrogen peroxide lower than $1 \times 10^{-6}$ M:

$$
i_{L}=0.62 n F A D_{\mathrm{H}_{2} \mathrm{O}_{2}}{ }^{2 / 3} v^{-1 / 6} C_{\mathrm{H}_{2} \mathrm{O}_{2}} \omega^{1 / 2}
$$

In Equation (1), $i_{L}$ is the mass-transfer limited current, $n$ is the number of electrons transferred, $A$ the electrode area, $F$ the Faraday constant, $D_{\mathrm{H}_{2} \mathrm{O}_{2}}$ the diffusion coefficient of hydrogen peroxide, $v$ the kinematic viscosity of the solution, $D_{\mathrm{H}_{2} \mathrm{O}_{2}}$ is the bulk concentration of hydrogen peroxide and $\omega$ is the electrode rotation rate. At concentrations of hydrogen peroxide higher than $1 \times 10^{-6}$ $\mathrm{M}$, a nonlinear behavior was observed. The responses of the rotating disc electrode prepared in [34] were very rapid. At $3000 \mathrm{rpm}, 95 \%$ of the steady-state current response could be reached in $2.3 \mathrm{~s}$.

\section{3) Effect of the applied potential}

The relationship between the response current and applied potential in $\mathrm{pH} 5.29$ buffer solution was also stud- 
ied for the $\mathrm{Hb} / \mathrm{POAP} / \mathrm{FeCoHCF} / \mathrm{Au}$ electrode [22]. The response current gradually increased with the applied potential from $0.3 \mathrm{~V}$ to $-0.25 \mathrm{~V}$ (vs. SCE) and then it decreased at a potential more negative than $-0.25 \mathrm{~V}$. Considering the possible interference effects and the operation stability of the electrode, $-0.25 \mathrm{~V}$ was selected in [22] as operating potential.

The applied potential did not significantly influence the response of the HRP-ferrocene/POAP biosensor when changes in the range $0.0 \mathrm{mV}$ to $100 \mathrm{mV}$ (vs. $\mathrm{Ag} / \mathrm{AgCl}$ ) were considered. However, at a potential more negative than $-100 \mathrm{mV}$, a rapid loss of activity was observed due to the irreversible reduction of the immobilized HRP (Figure 6).

\section{4) Effect of the interferents}

With regard to effects of electroactive interferents on the response current of the $\mathrm{Hb} / \mathrm{POAP} / \mathrm{FeCoHCF} / \mathrm{Au}$ electrode, the influence of $\mathrm{AA}, \mathrm{UA}$ and $\mathrm{AP}$ on the response current to $\mathrm{H}_{2} \mathrm{O}_{2}$ was analyzed in [22]. The observed response currents to AA, UA and AP at the $\mathrm{Hb} / \mathrm{POAP} / \mathrm{Au}$ electrode were very small. The good anti-interferent ability of the $\mathrm{Hb} / \mathrm{POAP} / \mathrm{FeCoHCF} / \mathrm{Au}$ electrode was assigned to the low potential applied $(-0.25 \mathrm{~V})$ and the selective permeability of the POAP film. However, the effect of electroactive interferents on the response current is really not obvious due to the low applied potential. The low conductivity and small porous size of the POAP film did not allow a detailed investigation of the effect of electroactive interferents. However, the response time of the $\mathrm{Hb} / \mathrm{POAP} / \mathrm{FeCoHCF} / \mathrm{Au}$ electrode is very fast (within $5 \mathrm{~s}$ ) and this short response time, as compared with those of other sensors, was attributed to the presence of the thin non-conducting POAP film.

5) Stability of hydrogen peroxide biosensors

The stability of the HRP-ferrocene/POAP electrode

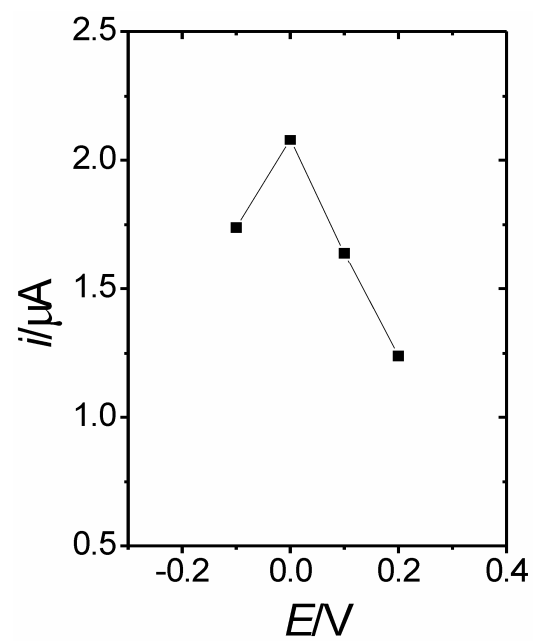

Figure 6. Effect of operating potential on the response of the HRP-ferrocene/POAP electrode $\left(5 \mathrm{mM}, 10\right.$ cycles, $50 \mathrm{mV} \cdot \mathrm{s}^{-1}$ to $10^{-4} \mathrm{M}$ injections of $\mathrm{H}_{2} \mathrm{O}_{2}[34]$. stored at room temperature in acetate buffer $(\mathrm{pH} 5)$ was investigated in [34]. A 43\% decrease in response was observed after 7 days. However, the POAP-modified electrode was stable during at least a period of 6 successive days.

6) Reproducibility and sensitivity of the biosensors

The HRP-ferrocene/POAP sensor [34] shows a linear response in the concentration range $1 \times 10^{-8} \mathrm{M}$ to $2 \times$ $10^{-6} \mathrm{M}$ of $\mathrm{H}_{2} \mathrm{O}_{2}$, with a slope, intercept and correlation coefficient of $6.47 \times 10^{-7} \mathrm{nA} \cdot \mathrm{M}^{-1}, 2.17 \mathrm{nA}$ and $0.9995(n$ $=10$ ), respectively. A series of injections of $10^{-5} \mathrm{M} \mathrm{H}_{2} \mathrm{O}_{2}$ yielded a standard deviation of $0.8 \%$, which remained constant after 300 injections (50 injections per day during a period of six successive days).

\section{7) Real sample analysis}

Hydrogen peroxide may be used as a preservative in milk. However, the legal situation in the different countries has to be considered. Sufficient sterilization is obtained at $0.1 \%$ hydrogen peroxide. The catalase present in the milk gradually destroys the $\mathrm{H}_{2} \mathrm{O}_{2}$. Hydrogen peroxide is also used for cleaning instruments and equipment used for cooling, mixing, transporting, bottling and packing milk. If the subsequent washing and drying is incomplete, the foodstuff is (illegally) contaminated with $\mathrm{H}_{2} \mathrm{O}_{2}$. In order to demonstrate the application of the HRP-ferrocene/POAP electrode [34] to real samples, the $\mathrm{H}_{2} \mathrm{O}_{2}$ concentration in a spiked milk sample containing $1.037 \pm 0.003 \mathrm{mg} \cdot \mathrm{mL}^{-1}$ (for $n=3$ ) of $\mathrm{H}_{2} \mathrm{O}_{2}$ was measured. The $\mathrm{H}_{2} \mathrm{O}_{2}$ concentration in the spiked milk samples, determined by the four-point calibration curve prepared using standard $\mathrm{H}_{2} \mathrm{O}_{2}$ constructed prior to the measurement, was found to be $1.083 \pm 0.054 \mathrm{mg} \cdot \mathrm{mL}^{-1}$ (for $n=3$ ). A blank milk sample was tested in the same way and did not show any signal.

\subsection{A Uric Acid Selective Biosensor Based on POAP}

The detection, identification and quantification of uric acid (2,6,8-trihydroxipurine) in human physiological fluids is of great importance in the diagnosis and therapy of patients suffering from a range of disorders associated with altered purine metabolism, most notably gout and hyperuricemia. Other medical conditions, such as leukemia and pneumonia, have been associated with enhanced urate levels. POAP has been successfully used in the development of a uric acid (UA) biosensor [35]. The biosensor was obtained by immobilizing uricase and horseradish peroxidase (HRP) $(7 \% w / w$ uricase and $3 \% w / w$ HRP) in carbon paste. Then, POAP was deposited on the working surface area of the electrode to obtain the $\mathrm{CP} /$ HRP-uricase/POAP biosensor. The response of the electrode is based on the enzymatic reduction of hydrogen peroxide in the presence of UA. Cyclic voltammetry and hydrodynamic studies were carried out in [35] order to 
ensure that current signals were due to enzymatically generated $\mathrm{H}_{2} \mathrm{O}_{2}$ and not due to direct electron transfer of UA at the working surface electrode. In this regard, cyclic voltammograms for both an unmodified carbon paste electrode (bare electrode) and a POAP-coated electrode were compared in solutions containing UA. POAP-coated electrodes yielded signals $50 \%$ smaller in magnitude, as compared with the unmodified electrode. This was attributed to the imposition of an additional diffusion barrier in the presence of POAP. The ratio between the current at the POAP-coated electrode and that of the bare electrode was considered as a measure of the coating permeability. Hydrodynamic studies also indicated that the electrocatalytic reduction of $\mathrm{H}_{2} \mathrm{O}_{2}$ by HRP immobilized on the CP electrode takes place without elec-tronmediating substances, which suggests that peroxidase is by itself capable of performing electron-transfer to the electrode.

\subsubsection{Influential Factors in the Response Characteristic of the Uric Acid Biosensor 1) Preparation of POAP films}

The effect of increasing the monomer (o-aminophenol) (o-AP) concentration during the electropolymerization process was explored in [35]. The most suitable monomer concentration for POAP coating was found to be $5 \times$ $10^{-3} \mathrm{M}$, even though a 10 times lower concentration improved response times and showed more rapid returns to base-line levels. In this regard, faster response times were recorded (24 s) for a polymer layer built in a $5 \times$ $10^{-4} \mathrm{M}$ concentration of o-AP.

\section{2) Effect of the solution $\mathrm{pH}$}

The behavior of the biosensor reported in [35] was studied within the $\mathrm{pH}$ range 5.0 - 9.0. Greater sensitivity was achieved at a $\mathrm{pH}$ value of 6.6. However, a $\mathrm{pH}$ value of 7.5 was selected in order to mimic the microenvironment of physiological fluids and to promote the longterm stability of the sensor.

\section{3) Effect of the applied potential}

Hydrodynamic voltammograms were recorded over the potential range $-0.1 \mathrm{~V}$ to $0.35 \mathrm{~V}$ (vs. $\mathrm{Ag} / \mathrm{AgCl}$ ). Then, steady-state currents were recorded and plotted as a function of the applied potential. At potential values more negative than $-0.2 \mathrm{~V}$, a rapid loss of activity was observed due to irreversible reduction of HRP. As the degradation of POAP occurs at high positive potential values, an operating potential of $0.05 \mathrm{~V}$ was selected for amperometric measurements in [35].

\section{4) Effect of the interferents}

A range of naturally occurring substances in blood were examined in [35] for their potential interference effects. Ascorbic acid gave approximately $2 \%$ and $15 \%$ increase in signal intensity for mean $\left(2.8 \times 10^{-4} \mathrm{M}\right)$ and upper $\left(3.41 \times 10^{-4} \mathrm{M}\right)$ levels found in blood, respectively.
The presence of bilirubin was found to have a detrimenttal effect on urate signals. A concentration of $1.7 \times 10^{-4}$ $M$ resulted in a decrease of $35 \%$ in signal intensity. As bilirubin was considered too large to pass through the polymer layer, the effect was attributed to some form of interaction with uric acid at the working surface area of the electrode, resulting in a diminished current. The influence of allopurinol on uric acid amperometric signals was also examined. It is well-known that the oxidized form of the drug binds tightly to the reduced form of the enzyme. Repeated injections of UA $\left(1 \times 10^{-4} \mathrm{M}\right)$ were carried out in the presence and absence of the drug. A reduction in current signal of $10.5 \%$ was noted. Two possibilities were considered to explain this effect: the first one is that oxidation of allopurinol interferes with the oxidase catalytic mechanism, and the second one is an effect of blockage (or interaction) at the working electrode surface.

\section{5) Stability of the biosensor}

The sensor response was found to be stable for 2 days while stored in the background electrolyte $(0.1 \mathrm{M}$ solution of phosphate buffer, $\mathrm{pH}$ 6.5) at room temperature $\left(25^{\circ} \mathrm{C}\right)$.

\section{6) Analysis of serum samples}

Serum samples containing different concentrations of UA were analyzed using the sensor described in [35]. Samples were diluted 1:10 with the supporting electrolyte solution and the $\mathrm{pH}$ adjusted at 7.5. Diluted samples were then directly injected into a flow system, and the concentration of UA was estimated from a calibration plot (Table 1). Results were in reasonable agreement with those determined by UV spectrophotometry. Repeated exposure of the electrode to diluted serum had no adverse effect on the amperometric signal size.

\subsection{A Lactate Amperometric Biosensor Based on $\operatorname{Poly}(O-P h e n y l e n e d i a m i n e)$ and Poly(O-Aminophenol) (PPD-POAP)}

L-lactate is an important analyte in a number of different situations including clinical, food and bioprocesses analyses. A reagentless lactate amperometric biosensor, constructed by immobilizing pyruvic transaminase (GPT) and $L$-lactate dehydrogenase (LDH) together with its cofactor, nicotinamide adenine dinucleotide $\left(\mathrm{NAD}^{+}\right)$, in carbon paste using a poly(o-phenylenediamine) (PPD) film (CP/LDH-GPT-NAD $\left.{ }^{+} / \mathrm{PPD}\right)$ has been, described [36]. Interference by direct electrochemical oxidation of easily oxidizable substances, such as uric acid, $L$-ascorbic acid, $L$-cysteine, glutathione and paracetamol, was drastically reduced by covering the PPD-modified electrode with a second electrochemically synthesized nonconducting POAP film (CP/LDH-GPT-NAD ${ }^{+} /$POAP-PPD). The response of both electrodes, $\left(\mathrm{CP} / \mathrm{LDH}-\mathrm{GPT}-\mathrm{NAD}{ }^{+} / \mathrm{PPD}\right.$ and $\mathrm{CP} / \mathrm{LDH}-$ 
GPT-NAD ${ }^{+}$/POAP-PPD) is based on the electrocatalytic oxidation, at low applied potentials, of the enzymatically produced NADH by the conducting PPD film. The bienzyme-double polymeric layer modified electrode, at an applied potential of $0.0 \mathrm{~V}$ (vs. $\mathrm{Ag} / \mathrm{AgCl}$ ), gives a linear response for lactate up to $8.5 \times 10^{-5} \mathrm{M}\left(1 / \mathrm{nA}=5.2 \times 10^{5}\right.$ [Lactate] $/ \mathrm{M}+0.5 r=0.9999 n=17)$ with a detection limit of $6 \times 10^{-7} \mathrm{M}$ (Table 1). The sensitivity to lactate of the POAP-PPD-modified electrode, and at an applied potential of $0.0 \mathrm{~V}$ (vs. $\mathrm{Ag} / \mathrm{AgCl}$ ), is about $50 \%$ lower than that of the PDD-modified electrode at $0.15 \mathrm{~V}$. In spite of this, the use of the POAP-PPD-modified electrode improved by $1-2$ orders of magnitude the sensitivity and detection limit of lactate determination when compared with other lactate biosensors based on the use of LDH and immobilized mediators. The CP/LDH-GPT$\mathrm{NAD}^{+} /$POAP-PPD electrode was used for the determination of L-lactate in cider. A good correlation was found between the results obtained from the sensor and those from spectrophotometric methods.

\subsection{Electrocatalytic Detection of Nicotinamide Coenzymes by POAP}

Although dehydrogenases dependent upon the nicotinamide adenine dinucleotide $\left[\left(\mathrm{NAD}(\mathrm{P})^{+}\right]\right.$cofactors are routinely used in a large number of solution phase enzymatic assays, they have been little used for the development of biosensors. A major problem in the dehydrogenase biosensor design is the regeneration of the oxidized coenzyme. Voltammetric and amperometric detection of $\mathrm{NAD}(\mathrm{P}) \mathrm{H}$ (dihydronicotinamide adenine dinucleotides) has been shown to be feasible at POAP-modified electrodes [37]. Voltammetric studies [37] demonstrate that POAP can be used in the electrocatalytic detection of nicotinamide coenzymes. The electrocatalytic behavior of POAP results from a chemical interaction (reaction) between the active sites of the polymer and the adsorbed molecules (NADH or NADHP).

\subsubsection{Influential Factors in the Response Characteristic of POAP in the Nicotinamide Coenzyme Detection \\ 1) Effect of the POAP thickness}

POAP films were grown in [37] on carbon paste electrodes by potential cycling. The catalytic amperometric response of POAP-modified electrodes to NADH was evaluated as a function of the composition and $\mathrm{pH}$ of the electropolymerization solution, the monomer concentration and the number of potential scan cycles applied to the electrode during polymer film formation (thickness of the polymer). It was found that the catalytic oxidation of NADH does not depend on the electrolyte used $(\mathrm{NaCl}$, $\mathrm{Na}_{2} \mathrm{HPO}_{4}, \mathrm{Na}_{2} \mathrm{SO}_{4}, 1$-heptanesulphonic acid) in the film formation process nor on the film thickness. With regard to the solution $\mathrm{pH}$, POAP-modified electrodes were prepared in background solutions of $\mathrm{pH}$ ranging from 1 to 9 at a monomer concentration of $5 \times 10^{-4} \mathrm{M}$. POAP generated in this $\mathrm{pH}$ range always displayed catalytic activity, but the catalytic current was higher for the film prepared at $\mathrm{pH} 1$ and 3 (Figure 7) due to the higher conductivity of POAP at low pH values. Despite the higher electroactivity exhibited by POAP films prepared in solutions of low $\mathrm{pHs}, \mathrm{pH}>5$ acetate buffer was preferred in [37] because a significant loss of enzymatic activity occurs when more acidic solutions are used.

\section{2) Effects of $\mathbf{p H}$ and applied potential}

The POAP-modified electrodes were used for cyclic voltammetry or amperometric measurements of NADH or NADPH in $0.1 \mathrm{M}$ phosphate buffer of $\mathrm{pH}$ 7. Cyclic voltammetry shows that, the uncatalyzed oxidation of $\mathrm{NADH}$ at a bare carbon paste electrode in $\mathrm{pH} 7$ phosphate buffer yields a single irreversible peak at $c a 0.5 \mathrm{~V}$ (vs. $\mathrm{Ag} / \mathrm{Ag} / \mathrm{Cl}$ ). The electrocatalytic activity of the POAP-modified carbon paste electrode for the oxidation of NADH was demonstrated by the appearance of an anodic current starting at potentials below $0.0 \mathrm{~V}$ and a pre-wave with a half-wave potential of $0.20 \mathrm{~V}$. A second anodic process appears at a potential close to that corresponding to uncatalyzed NADH oxidation at a bare carbon paste electrode $(0.5 \mathrm{~V})$. An analogous cyclic voltammetric behavior for NADH was also observed for NADPH. The effect of the potential scan on the pre-wave limiting current and the uncatalyzed oxidation peak current of NADH was also examined for POAP-modified

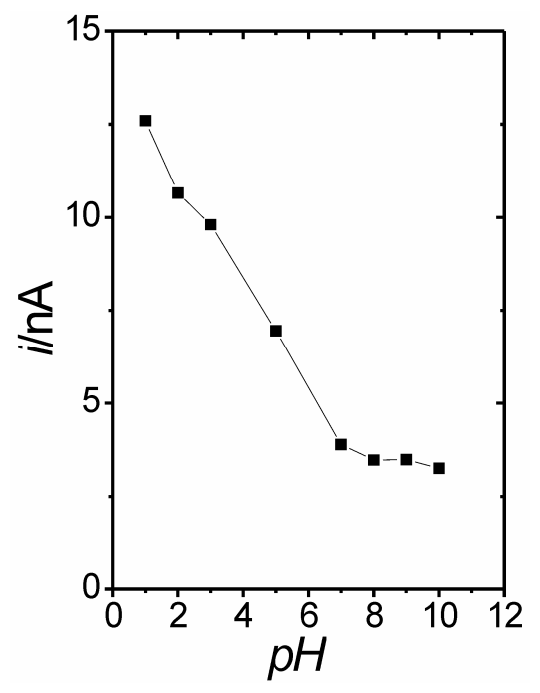

Figure 7. Amperometric currents developed by a POAPmodified electrode for $1.0 \times 10^{-5} \mathrm{M}$ NADH as a function of the electropolymerization $\mathrm{pH}$ medium. Applied potential $0.15 \mathrm{~V}$ (Ag/AgCl). Supporting electrolyte for the amperometric measurements: $0.1 \mathrm{M}$ phosphate buffer $\mathrm{pH} 7$ [37]. 
carbon paste electrodes. The peak current was found to be linearly related to the square root of the potential scan rate within the tested range $2-20 \mathrm{mV} \cdot \mathrm{s}^{-1}$, indicating that this process is diffusion-controlled. Nevertheless, the pre-wave limiting current remains constant at different potential scan rates. An entirely analogous behavior was found for NADPH oxidation. It has been demonstrated that the POAP-modified carbon paste electrode lowers the oxidation overpotential of NADH and NADHP [37].

Hydrodynamic voltammograms for the unmodified and POAP-modified carbon paste electrodes have also been compared [37]. There was no appreciable oxidation of NADH or NADPH at the bare carbon paste electrode up to $0.3 \mathrm{~V}$. For the POAP-modified carbon paste electrode a plateau was obtained for NADH oxidation at potentials between 150 and $300 \mathrm{mV}$, whereas the NADPH oxidation occurs at more positive potentials close to the uncatalyzed coenzyme oxidation. The amperometric response of POAP-modified electrodes to increasing concentrations of NADH and NADPH was also investigated using stationary working electrodes in magnetically stirred solutions.

Calibration plots were obtained in $0.1 \mathrm{M}$ acetate buffer at $\mathrm{pH} 5.0$ and $0.1 \mathrm{M}$ phosphate buffer $\mathrm{pH}$ 7. With regard to the catalytic activity of POAP, a current value of about $0.16 \mathrm{nA}$ for $1.0 \times 10^{-7} \mathrm{M} \mathrm{NADH}$ at $\mathrm{pH} 7$ was reported in [37]. The time required to obtain a steady-state response was less than $15 \mathrm{~s}$. The detection limit was close to $1.0 \times$ $10^{-9} \mathrm{M}$. Even though POAP-modified carbon paste electrodes are suitable for NADH detection in aqueous solutions, for NADPH detection a polymer such as poly(ophenylenediamine) seems to be more appropiate.

\subsection{POAP as a Molecular Imprinting Material for Sensor Preparation}

Molecular imprinting is a means of synthesizing some polymers with selectivity to some particular molecules (template molecules) developed in recent years. Molecularly imprinted polymers usually have some cavities with a given size and shape and arraying functional groups, so they lend some memorial function to the specific steric structures of template molecules, thus endowing them with good recognition ability. Traditionally, molecularly imprinted polymers prepared by routine methods, such as castings, in-situ polymerization, spin coating, etc., are generally of a thickness over a micron and are poorly homogeneous, influencing the sensitivity and the final design of sensors to a certain degree. In this regard, an electrochemical sensor for nicotine based on the electropolymerization of a molecular imprinting polymer with $o$-aminophenol as monomer and nicotine as template was analyzed in [38]. Compared with nicotine imprinting membranes, the electropolymerization film of POAP had the following advantages: it was homogeneous, the thick- ness was of the order of the nanometer and its preparation was simple. In this regard, by employing cyclic voltammetry and weak acidity conditions, the sensor was prepared by electropolymerization of o-AP on a gold electrode in the presence of the template (nicotine). The determination limit was $2.0 \times 10^{-7} \mathrm{~mol} \cdot \mathrm{L}^{-1}$, and a linear relationship between current and concentration in the range $4.0 \times 10^{-7}-3.3 \times 10^{-5} \mathrm{~mol} \cdot \mathrm{L}^{-1}$ was reported. The sensor was applied to the analysis of nicotine in tobacco samples with recovery rates from $99.0 \%$ to $102 \%$.

The preparation and properties of electrosynthesized POAP, as a molecular imprinting material, were also studied in [39] by the in-situ Quartz Crystal Impedance method. 2,4-Dichlorophenoxyacetic acid was employed as template molecule. During the polymerization, the changes of frequency $\left(\Delta f_{\mathrm{o}}\right)$, resistance $\left(\Delta R_{\mathrm{o}}\right)$ and capacitance $\left(\Delta C_{\mathrm{o}}\right)$ of the equivalent circuit were analyzed on the basis of the Butterworth-Van Dyke model. The thickness shear mode acoustic sensor modified with this material exhibited molecular recognition ability to the template molecule. In the range $4.0 \times 10^{-5}$ to $2.0 \times 10^{-3} \mathrm{M}$, a linear relationship between the frequency shift $\left(-\Delta f_{\mathrm{o}}\right)$ and $\log C$ was found from the calibration curve. The determination limit was $1.0 \times 10^{-5} \mathrm{M}$.

\section{Conclusion}

For many years, among different research groups, our group has studied the electrochemical properties of poly (o-aminophenol) in acidic media. The effects of different external variables, such as applied potential, solution composition and $\mathrm{pH}$, threshold potential for deactivation, etc., on the conduction properties of this polymer have been analyzed in detail. It has been observed that the applied potentials are slightly higher than $0.5 \mathrm{~V}$ (vs. SCE) and the electrolyte media of relatively high $\mathrm{pH}$ strongly decrease POAP conductivity. These conditions, combined with the intrinsic low permeability of POAP towards species in solution, are negative factors, which should restrict the practical uses of POAP. However, the recent literature, describing numerous applications of POAP in the field of biosensors, has demonstrated that the isolating properties of POAP synthesized in neutral media are very useful in preventing the biosensor from fouling and eliminating the interference from electroactive species, which is essential in obtaining a selective response currently. Researchers within the sensor field are increasingly taking advantage of the isolating properties of poly(oaminophenol), and showing the polymer to have considerable utility when they were initially considered to have low practical value.

\section{Acknowledgements}

R. Tucceri gratefully acknowledges the Consejo Nacio- 
nal de Investigaciones Científicas y Técnicas (CONICET) and the Facultad de Ciencias Exactas, National University of La Plata (UNLP).

\section{REFERENCES}

[1] G. Inzelt, M. Pineri, J. W. Schulttze and M. A. Vorotyntsev, "Electron and Proton Conducting Polymers: Recent Developments and Prospects," Electrochimica Acta, Vol. 45, No. 15-16, 2000, pp. 2403-2421. doi:10.1016/S0013-4686(00)00329-7

[2] C. Barbero, J. J. Silber and L. Sereno, "Formation of a Novel Electroactive Film by Electropolymerization of ortho-Aminophnol. Study of Its Chemical Structure and Formation Mechanism. Electropolymerization of Analogous Compounds," Journal of Electroanalytical Chemistry and Interfacial Electrochemistry, Vol. 263, No. 2, 1989, pp. 333-352. doi:10.1016/0022-0728(89)85103-4

[3] S. Kunimura, T. Ohsaka and N. Oyama, "Preparation of Thin Polymeric Films on Electrode Surfaces by Electropolymerization of $o$-Aminophenol," Macromolecules, Vol. 21, No. 4, 1988, pp. 894-900. doi:10.1021/ma00182a007

[4] C. Barbero, J. Zerbino, L. Sereno and D. Posadas, "Optical Properties of Electropolymerized Orthoaminophenol," Electrochimica Acta, Vol. 32, No. 4, 1987, pp. 693-697. doi:10.1016/0013-4686(87)87063-9

[5] T. Ohsaka, S. Kunimura and N. Oyama, "Electrode Kinetics of Poly(o-Aminophenol) Film Prepared by ElectroOxidative Polymerization of $o$-Aminophenol and Its Electrochromic Properties," Electrochimica Acta, Vol. 33, No. 5, 1988, pp. 639-645. doi:10.1016/0013-4686(88)80062-8

[6] A. Guenbourg, A. Kacemi, A. Benbachir and L. Aries, "Electropolymerization of 2-Aminophenol. Electrochemical and Spectroscopic Studies," Progress in Organic Coatings, Vol. 38, No. 2, 2000, pp. 121-127. doi:10.1016/S0300-9440(00)00085-0

[7] J. M. Ortega, "Studies of Poly(o-Aminophenol) by Quartz Crystal Impedance Measurements," Synthetic Metals, Vol. 97, No. 2, 1998, pp. 81-84. doi:10.1016/S0379-6779(98)00088-5

[8] A. Q. Zhang, C. Q. Cui, Y. Z. Chen and J. Y. Lee, "Synthesis and Electrochromic Properties of Poly-o-Aminophenol," Journal of Electroanalytical Chemistry and Interfacial Electrochemistry, Vol. 373, No. 1-2, 1994, pp. 115-121. doi:10.1016/0022-0728(94)03329-3

[9] C. Barbero, J. J. Silber and L. Sereno, "Electrochemical Properties of Poly-ortho-Aminophenol Modified Electrodes in Aqueous Acid Solutions," Journal of Electroanalytical Chemistry and Interfacial Electrochemistry, Vol. 291, No. 1-2, 1990, pp. 81-101. doi:10.1016/0022-0728(90)87179-N

[10] C. Barbero, R. I. Tucceri, D. Posadas, J. J. Silber and L. Sereno, "Impedance Characteristics of Poly-o-Aminophenol Electrodes," Electrochimica Acta, Vol. 40, No. 8, 1995, pp. 1037-1040. doi:10.1016/0013-4686(94)00373-9

[11] R. I. Tucceri, "Surface Resistance Measurements on Thin Gold Film Electrodes Coated with Poly(o-Aminophenol) Films," Journal of Electroanalytical Chemistry and In- terfacial Electrochemistry, Vol. 505, No. 1-2, 2001, pp. 72-84. doi:10.1016/S0022-0728(01)00467-3

[12] R. I. Tucceri, "Specularity Change on a Thin Gold Film Surface Coated with Poly(o-Aminophenol) during the Polymer Redox Conversion. The $\mathrm{pH}$ Effect on the Redox Sites Distribution at the Metal-Polymer Interface," Journal of Electroanalytical Chemistry and Interfacial Electrochemistry, Vol. 543, No. 1, 2003, pp. 61-71. doi:10.1016/S0022-0728(02)01482-1

[13] R. Tucceri, "A Review about the Surface Resistance Technique in Electrochemistry," Surface Science Reports, Vol. 56, No. 3-4, 2004, pp. 85-157. doi:10.1016/j.surfrep.2004.09.001

[14] R. I. Tucceri, "The Change of the Electron Scattering at the Gold Film-Poly(o-Aminophenol) Film Interface after Partial Degradation of the Polymer Film: Its Relation with the Electron Transport Process within the Polymer Film," Journal of Electroanalytical Chemistry and Interfacial Electrochemistry, Vol. 562, No. 2, 2004, pp. 173181. doi:10.1016/j.jelechem.2003.09.003

[15] T. Komura, Y. Ito, Y. T. Yamaguti and K. Takahasi, "Charge-Transport Processes at Poly-o-Aminophenol Film Electrodes: Electron Hopping Accompanied by Proton Exchange," Electrochimica Acta, Vol. 43, No. 7, 1998, pp. 723-731. doi:10.1016/S0013-4686(97)00202-8

[16] O. Levin, V. Kondratiev and V. Malev "Charge Transfer Processes at Poly-o-Phenylenedialmine and Poly-o-Aminophenol," Electrochimica Acta, Vol. 50, No. 7-8, 2005, pp. 1573-1585. doi:10.1016/j.electacta.2004.10.028

[17] F. J. Rodríguez Nieto, D. Posadas and R. Tucceri, "Effect of the Bathing Electrolyte Concentration on the Charge Transport Process at Poly(o-Aminophenol) Modified Electrodes. An ac Impedance Study," Journal of Electroanalytical Chemistry and Interfacial Electrochemistry, Vol. 434, No. 1-2, 1997, pp. 83-91. doi:10.1016/S0022-0728(97)00235-0

[18] F. J. Rodríguez Nieto and R. Tucceri, "The Effect of $\mathrm{pH}$ on the Charge Transport at Redox Polymer-Modified Electrodes: An a.c. Impedance Study Applied to Poly $(o-A m i-$ nophenol) Film Electrodes," Journal of Electroanalytical Chemistry and Interfacial Electrochemistry, Vol. 416, No. 1-2, 1996, pp. 1-24. doi:10.1016/S0022-0728(96)04704-3

[19] J. M. Ortega, "Conducting Potential Range of Poly $(o-$ Aminophenol)," Thin Solid Films, Vol. 371, No. 1-2, 2000, pp. 28-35. doi:10.1016/S0040-6090(00)00980-9

[20] A. Bonfranceschi, A. Pérez Córdoba, S. Keunchkarian, S. Zapata and R. Tucceri, "Transport across Poly(o-Aminophenol) Modified Electrodes in Contact with Media Containing Redox Couples Species. A Study Using Rotating Disc Electrode Voltammetry," Journal of Electroanalytical Chemistry and Interfacial Electrochemistry, Vol. 477, No. 1, 1999, pp. 1-13. doi:10.1016/S0022-0728(99)00368-X

[21] R. Tucceri, "The Effect of High Positive Potentials on the Different Charge Transport and Charge Transfer Parameters of Poly (o-Aminophenol) Modified Electrodes. A Study Using Cyclic Voltammetry, Steady-State Rotating Disc Electrode Voltammetry and Ac Impedance Measurements," Journal of New Materials for Electrochemical 
Systems, Vol. 8, No. 4, 2005, pp. 305-315.

[22] W. Tao, D. Pan, Y. Liu, L. Nie and S. Yao, "An Amperometric Hydrogen Peroxide Sensor," Analytical Biochemistry, Vol. 338, No. 2, 2005, pp. 332-340.

doi:10.1016/j.ab.2004.12.009

[23] A. Guerrieri, R. Ciriello and D. Centonze, "Permselective and Enzyme-Entrapping Behaviors of an Electropolymerized, Non-Conducting, Poly(o-Aminophenol) Thin FilmModified Electrode. A Critical Study," Biosensors and Bioelectronics, Vol. 24, No. 6, 2009, pp. 1550-1556. doi:10.1016/j.bios.2008.08.004

[24] C. G. J. Koopal and R. J. M. Nolte, "An Amperometric Biosensor Based on Polypyrrole," Bioelectrochemistry and Bioenergetics, Vol. 33, No. 1, 1994, pp. 45-53. doi:10.1016/0302-4598(94)87031-4

[25] S. Cosnier and H. Gunther, "A Polypyrrole $\left[\mathrm{Rh}(\mathrm{III})\left(\mathrm{C}_{5} \mathrm{Me}_{5}\right)(\mathrm{bpy}) \mathrm{Cl}\right]^{+}$Modified Electrode for the Reduction of $\mathrm{NAD}^{+}$Cofactor," Journal of Electroanalytical Chemistry and Interfacial Electrochemistry, Vol. 315, No. 1-2, 1991, pp. 307-315. doi:10.1016/0022-0728(91)80079-6

[26] N. C. Foulds and C. R. Lowe, "Immobilization of Glucose Oxidase in Ferrocene-Modified Pyrrole Polymers," Analytical Chemistry, Vol. 60, No. 22, 1988, pp. 2473-2478. doi:10.1021/ac00173a008

[27] S. Lu, C. Li, D. Zhang, Y. Zhang, Z. Mo, Q. Cai and A. Zhu, "Electron Transfer on an Electrode of Glucose Oxidase Immobilized in Polyaniline," Journal of Electroanalytical Chemistry and Interfacial Electrochemistry, Vol. 364, No. 1-2, 1994, pp. 31-36. doi:10.1016/0022-0728(93)02928-B

[28] D. Pan, J. Chen, L. Nie, W. Tao and S. Yao, “Amperometric Glucose Biosensor Based on Immobilization of Glucose Oxidase in Electropolymrized $o$-Aminophenol Film at Prussian Blue-Modified Platinum Electrode," Electrochimica Acta, Vol. 49, No. 5, 2004, pp. 795-801. doi:10.1016/j.electacta.2003.09.033

[29] X. Chen, J. Chen, C. Deng, C. Xiao, Y. Yang, Z. Nie and S. Yao, "Amperometric Glucose Biosensor Based on Boron-Doped Carbon Nanotubes Modified Electrode," Talanta, Vol. 76, No. 4, 2008, pp. 763-767. doi:10.1016/j.talanta.2008.04.023

[30] D. Pan, J. Chen, S. Yao, W. Tao and L. Nie, "An Amperometric Glucose Biosensor Based on Glucose Oxidase Immobilized in Electropolymerized Poly(o-Aminophenol) and Carbon Nanotubes Composite Film on a Gold Electrode," Analytical Sciences, The Japan Society for Analytical Chemistry, Vol. 21, No. 4, 2005, pp. 367-371.
[31] Z. Zhang, H. Liu and J. Deng, "A Glucose Biosensor Based on Immobilization of Glucose Oxidase in Electropolymerized $o$-Aminophenol Film on Platinized Glassy Carbon Electrode," Analytical Chemistry, Vol. 68, No. 9, 1996, pp. 1632-1638. doi:10.1021/ac950431d

[32] J. Li and X. Lin, "Glucose Biosensor Based on Immobilization of Glucose Oxidase in Poly(o-Aminophenol) Film on Polypyrrole-Pt Nanocomposite Modified Glassy Carbon Electrode," Biosensors and Bioelectronics, Vol. 22, No. 12, 2007, pp. 2898-2905. doi:10.1016/i.bios.2006.12.004

[33] A. Q. Zhang, C. Q. Cui and J. Y. Lee, "Metal-Polymer Interaction in the $\mathrm{Ag}^{+}$/Poly-o-Aminophenol System," Journal of Electroanalytical Chemistry and Interfacial Electrochemistry, Vol. 413, No. 1-2, 1996, pp. 143-151. doi:10.1016/0022-0728(96)04668-2

[34] M. A. Valdés García, P. Tuñón Blanco and A. Ivaska, “A Poly(o-Aminophenol) Modified Electrode as an Amperometric Hydrogen Peroxide Biosensor," Electrochimica Acta, Vol. 43, No. 23, 1998, pp. 3533-3539. doi:10.1016/S0013-4686(98)00101-7

[35] E. Miland, A. J. Miranda Ordieres, P. Tuñón Blanco, M. R. Smyth and C. O. Fágáin, "Poly(o-Aminophenol)-Modified Bienzyme Carbon Paste Electrode for the Detection of Uric Acid," Talanta, Vol. 43, No. 5, 1996, pp. 785-791. doi:10.1016/0039-9140(95)01825-5

[36] J. Lobo Castañón, A. J. Miranda Ordieres and P. Tuñón Blanco, "A Bienzyme-Poly(o-Phenylenediamine)-Modified Carbon Paste Electrode for the Amperometric Detection of L-Lactate," Analytica Chimica Acta, Vol. 346, No. 2, 1997, pp. 165-174. doi:10.1016/S0003-2670(97)00115-3

[37] M. J. Lobo, A. J. Miranda, J. M. López-Fonseca and P. Tuñón, "Electrocatalytic Detection of Nicotinamide Coenzymes by $\operatorname{Poly}(o$-Aminophenol) and Poly $(o$-Phenylenediamine)-Modified Carbon Paste Electrode," Analytica Chimica Acta, Vol. 325, No. 1-2, 1996, pp. 33-42. doi:10.1016/0003-2670(96)00022-0

[38] W. Zhaoyang, Z. Xiaolei, Y. Yunhui, S. Guoli and Y. Ruqin, "A Sensitive Nicotine Sensor Based on Molecularly Imprinted Electropolymer of o-Aminophenol," Frontiers of Chemistry in China, Vol. 1, No. 2, 2006, pp. 183-187.

[39] H. Peng, F. Yin, A. Zhou and S. Yao, "Characterization of Electrosynthesized Poly(o-Aminophenol) as a Molecular Imprinting Material for Sensor Preparation by Means of Quartz Crystal Impedance Analysis," Analytical Letters, Vol. 35, No. 3, 2002, pp. 435-450. doi:10.1081/AL-120002678 